\title{
Mulheres indígenas na web e as escritas de si como práticas de resistência
}

\author{
Indigenous women on the web and their self-writings as practices of resistance
}

\author{
Raimundo de Araújo TOCANTINS \\ Universidade da Amazônia (UNAMA)
}

ORCID ID: https://orcid.org/0000-0001-7176-1753

\begin{abstract}
RESUMO: O estudo aqui desenvolvido é parte integrante da tese intitulada "Mulheres Indígenas em Redes: cosmologias, singularidades históricas, resistências e conhecimentos em elaborações ativistas". O artigo de maneira específica empreende a compreensão sobre as maneiras de elaboração do protagonismo de mulheres indígenas presente na web, compreendido aqui como as narrativas de si nos espaços da internet. Neste intento, será desenvolvido no texto um percurso teórico que contempla os aspectos relativos à construção dessas narrativas: antigos e novos regimes de visualidades e o funcionamento da memória das imagens empreendidas em relação aos indígenas, que também desvelam as descontinuidades históricas presentes nessas narrativas, as convergências culturais e outros lugares de enunciação onde elas protagonizam as escritas de si como práticas de resistência. O corpus de análise apresenta dois enunciados construídos nas redes sociais por duas mulheres de diferentes etnias: Daiara Tukano e Célia Xakriabá.
\end{abstract}

Palavras-chave: Mulheres Indígenas. Ativismo. Narrativas de Si. Web. Práticas de Resistência.

ABSTRACT: The study developed here is an excerpt thesis entitled "Indigenous Women in Networks: cosmologies, historical singularities, resistance and knowledge in activist elaborations". The article in a specific way undertakes an understanding of the ways of preparing the protagonism of indigenous women present on the web, understood here as the self-writing narratives in the spaces of the internet. In this attempt, a theoretical path will be developed in the text that contemplates the aspects related to the construction of these narratives: old and new regimes of visualities and the functioning of the memory of the images undertaken in relation to the indigenous people, who also reveal as historical discontinuities present in these narratives, as cultural convergences and other places of enunciation where they play the role of self-writings as practices of resistance. The corpus of analysis presents two statements built on social networks by two women of different ethnicities: Daiara Tukano and Célia Xakriabá.

Keywords: Indigenous Women. Activism. Self-Writing Narratives. Web. Resistance Practices.

\section{Introdução às escritas de si como práticas de resistência}

A construção enunciativa de duas mulheres originárias de diferentes etnias desvela o protagonismo de indígenas ativistas na elaboração de narrativas nos espaços da web. Estas escritas de si envolvem diferentes e criativas narrativas contemporâneas elaboradas com o intuito de proteger seus corpos, territórios e cosmologias. Inscrever suas histórias 
narrativizar suas próprias histórias. Nesse sentido, elas feminizam, indigenizam e tornam mais diversos estes espaços por onde circulam e que constituem seu fazer ativista.

O protagonismo dessas indígenas convida a pensar com Michel Foucault (2004) sobre o "cuidado de si". Quando reflito sobre esta forma de cuidado, não aponto para o investimento em práticas sugeridas por instituições religiosas, essas correspondem a exercícios coercitivos que organizam os corpos e as almas no sentido de "uma moral da renúncia" visando ao controle. Os enunciados das indígenas na web falam de mulheres e suas práticas de si, para olhar os próprios corpos, “de um exercício de si sobre si mesmo através do qual se procura se elaborar, se transformar e atingir um certo modo de ser" (FOUCAULT, 2004, p. 265).

Para dar conta da complexidade das narrativas de mulheres indígenas na web, compreendemos este espaço sob a perspectiva de Gregolin (2015, p. 07), como "a heterotopia por excelência do século XXI. Nesse espaço virtual cruzam-se todo tipo de outros espaços, consensuais e conflitantes; acolhem-se todo tipo de enunciados e de formas de visibilidade". Nesses lugares, "nossos corpos atravessam, pela WEB, lugares e tempos que outrora eram inatingíveis e nos permitem novas experiências com o passado distante" (NEVES-CORREA 2019, p. 104).

Concatenado com essa visada, o artigo apresentará na sua arquitetura em um primeiro momento, a compreensão elaborada sobre os povos indígenas, empreendido pela perspectiva do colonizador europeu, compreendido como o primeiro a narrativizar as identidades indígenas. Nessa construção, mostro o papel inicial dos enunciados imagéticos e sua força no sentido de construir uma memória de futuro para os povos originários. Em seguida, analiso como as narrativas destas mulheres indígenas da contemporaneidade, nos espaços da internet, elaborados em lugares de convergências culturais, agora são as enunciadoras que contam sobre suas subjetividades, a partir de seus lugares de enunciação. Nestes espaços, as narrativas das indígenas revelam o cuidado de si em práticas de resistência e visibilizam o jogo das descontinuidades históricas.

\section{Regimes de visualidades e memória das imagens}

As narrativas elaboradas por mulheres indígenas ativistas em circulação nos espaços da web têm na imagem, sobretudo nas fotografias, uma materialidade importante na produção de sentidos. Esses enunciados visuais são uma das principais características das narrativas elaboradas por essas ativistas e são fundamentais nas análises. Dito isto, o segundo ponto a considerar é a centralidade do corpo nestas imagens, mas não a 
concepção de corpo apenas biológico e sim o corpo em sua densidade discursiva, um corpo-discurso.

\begin{abstract}
Para estarmos diante de um corpo discursivo não basta nos depararmos com práticas do fazer do nosso dia-a-dia. Precisamos focalizar a existência material desse objeto que denominamos corpo, em consonância com suas formas e carnes por meio da representação sob a qual o identificamos. Para tanto, precisamos considerar esse corpo do qual falamos, colocando em evidência a sua existência histórica, o seu status material, reafirmando o questionamento foucaultiano "quem fala?" (MILANEZ, 2009).
\end{abstract}

Historicamente, desde o início da colonização, os indígenas tiveram seus corpos, regimes alimentares, ambientes onde viviam, em suma, seus modos de vida discursivizados por não-indígenas. Ao longo de cinco últimos séculos, esta insistente exposição das imagens indígenas se apresenta aos olhos ocidentais, por isso são bem conhecidas as projeções das realidades indígenas nessas interpretações. Como não poderia deixar de ser, estas populações foram vítimas de distorções e muitas vezes de uma total falta de compreensão, devido ao distanciamento entre as realidades europeias e as sociedades que aqui viviam.

As imagens produzidas por esses enunciadores obedecem a relações de sentidos definidas por um discurso considerado "superior" e que construiu as bases para uma compreensão ocidentalizada sobre as subjetividades indígenas. Esse discurso forjado no encontro entre imagem e corpo sempre foi produzido de acordo com as tecnologias de seu tempo para produção de imagens e revelavam essas diferenças. Inicialmente, o desenho, em seguida a pintura, depois a fotografia, são materialidades que produziram diversas formas de compreensão dos corpos indígenas, mas que obedeciam ao discurso da sensualidade, selvageria, incivilização, que desde o início do contato destes povos com os europeus dominou a compreensão sobre estas identidades. Ao pensamos na relação entre a produção de imagens e, consequentemente, subjetividades, pensamos com Courtine (2011) e Hartman (1975), na articulação produzida entre enunciadores, determinados períodos históricos, suas especificidades técnicas e a construção discursiva produzida nessa relação, para compreendermos estes regimes de visualidade.

Thekla Hartmann (1975) argumenta sobre a produção de imagens indígenas e mostra como essas representações foram construídas sob diferentes situações como: olhares estéticos de determinadas correntes artísticas, alterações nos desenhos originais feitas "in loco", uso em algumas dessas imagens de um único "manequim" como modelo de corpo. Ela elenca uma série de fatores que interferem na condição documental e 
histórica dessas produções. As imagens que produzem um arquivo de memórias sobre os povos indígenas são discursos revelam diferentes regimes de visualidades, com suas determinações históricas e estéticas. Em outras palavras, estas representações, elaboradas sob outros regimes de visualidades, revelam as condições sob as quais foram forjados os discursos, em sua materialidade visual, que construíram para o Ocidente e para o futuro as subjetividades indígenas.

A clássica imagem do livro intitulado "Duas Viagens", lançado em meados do século XVI na Europa, serve para materializar um determinado regime de visualidade sobre os indígenas brasileiros. Este trabalho atribuído a Hans Staden, viajante mercenário alemão que ficou conhecido por ter realizado duas viagens ao Brasil no século XVI, apresenta aos olhos ocidentais, uma espécie de banquete canibal (figura 01). O desenho do livro do viajante alemão apresentou à Europa índios nus comendo pedaços de corpos humanos, como se isso fosse algo corriqueiro do cotidiano dos Tupinambá.

Figura 01: Banquete Canibal

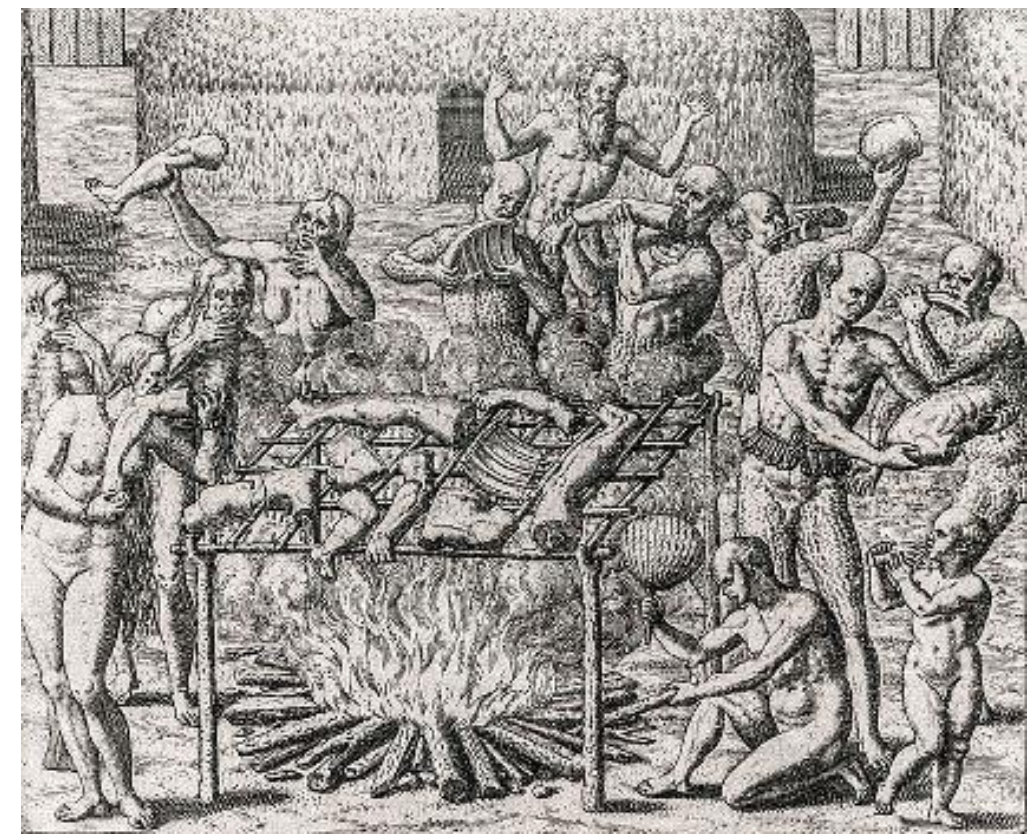

Fonte: https://www.researchgate.net/figure/Figura-2-Hans-Staden-ao-fundo-observando-um-ritual-antropofagico-TupinambaFonte_fig2_250029115

O ritual de antropofagia dos índios Tupinambá consistia na captura de outros indígenas, que eram aprisionados e devorados por eles. Porém, este ritual era realizado com seus prisioneiros de guerra considerados heróis. Havia uma ordem para esta prática, ao contrário da desordem canibal e do caos que o olhar europeu instituiu aos futuros leitores desta imagem como representação subjetiva do selvagem e do não civilizado. 
Em um primeiro olhar sobre a representação dos corpos na imagem, percebemos a partir da leitura de seus traços e vestígios quais modelos de corpos foram utilizados para retratar os indígenas brasileiros: vemos no plano central superior, na imagem à esquerda, a representação de um homem de braços, tórax e abdômen de músculos salientes. Além disso, seu rosto possui uma longa barba. Apesar desta figura central se diferenciar das outras representações do sexo masculino desta produção, também é possível perceber que os corpos no trabalho atribuído a Staden obedecem a uma ordem que nos remete às divindades gregas. A representação sobre os indígenas segue, nesse momento, a um regime de visualidade que se submete à visão eurocêntrica do autor e a olhares estéticos de determinadas correntes artísticas, como nos elucida Hartmann (1975).

Nesta direção, afinado com os estudos do discurso foucaultiano, lanço mão da caixa de ferramentas teóricas proporcionadas pelos estudos discursivos foucaultianos e sua articulação com a semiologia histórica. A definição de intericonicidade desenvolvida por Courtine $(2005,2011)$, a partir das bases teóricas formuladas pela releitura deste autor do livro "Arqueologia do Saber" (2005), de Michel Foucault, ajuda a compreender como os discursos estão imbricados em práticas não verbais, portanto, o "verbo não poderia mais ser dissociado do corpo e do gesto" (COURTINE, 2011, p.150).

A semiologia histórica, como categoria de leitura das imagens se oferece a esta análise como teoria para refletir sobre as transformações históricas no campo do discurso a partir de "regimes de práticas, séries de enunciados e redes de imagens" (COURTINE, 2011, p. 151). Dessa maneira, essa perspectiva fornece as bases para a leitura das imagens, para as análises referentes à natureza histórica dos processos discursivos presentes nos enunciados visuais produzidos inicialmente por outros enunciadores sobre os indígenas, e também para a compreensão em relação à produção enunciativa das próprias subjetividades indígenas na atualidade.

A semiologia histórica associada à compreensão de Hartmann (1975) deixa ver a dimensão de como essas produções impregnadas por olhares estéticos de determinadas correntes artísticas podem ser compreendidas como fragmentos da história. Elas revelam a produção de verdades sobre as subjetividades indígenas sob o viés do enunciador, no caso da figura 01, o olhar europeu, que apresentava uma versão forjada sobre essas identidades.

\section{Protagonismo de mulheres indígenas, regimes de visibilidade e resistência}


$\mathrm{Na}$ história do presente, com seus regimes de visibilidade próprios e seus novos lugares de enunciação, Daiara Tukano e Célia Xakriabá exibem na web, por meio de enunciados verbais e visuais com suas (re)elaborações identitárias. A partir dessa escrita de si, elas apresentam na internet suas práticas de resistências contemporâneas. As postagens nos perfis das indígenas são enunciados que também se inscrevem em novos acontecimentos. As fotografias, ainda que remetam de alguma forma ao funcionamento de jornais e revistas impressas, estão dentro de uma outra dinâmica de comunicação. As novas possibilidades das redes sociais se oferecem como um campo onde podemos perceber substanciais alterações na forma de conceber e receber os discursos em suas materialidades visuais sobre os corpos indígenas.

Para colocar em funcionamento a compreensão de história revestindo os corpos oferecidos por imagens que nos contam outras histórias e colocam nessa narrativa a assinatura daqueles e daquelas que antes tiveram suas biografias contadas por outros, proponho o exame de uma prática que irrompeu em um determinado momento da história humana. Refiro-me à criação das lives e suas possibilidades de comunicação a distância. Trata-se de uma forma de interação que acontece por meio da internet e requer o domínio dos meios digitais de comunicação. Em 2020, elas se tornaram extremamente utilizada, devido à pandemia do novo Coronavírus, que obrigou a humanidade a passar bem mais tempo diante das telas.

Diante da pandemia, as lives se tornaram um espaço muito significativo para o ativismo indígena. A posição do governo de Jair Bolsonaro diante dos povos indígenas demandou uma reação muito organizada e articulada para tentar reduzir as mortes. O primeiro enunciado a ser analisado será o da ativista Daiara Tukano. Delineado pelas artes plásticas e pela comunicação, o fazer ativista de Daiara Tukano dialoga com a cosmovisão Tukano. Daiara nasceu em São Paulo, em uma família de lideranças indígenas com forte atuação no momento de redemocratização do país. Esta mulher indígena atualmente mora em Brasília, onde é correspondente da Rádio Yandê, primeira web rádio indígena do Brasil. A arte educadora decolonial, reconstrói detalhes de sua vivência entre os Tukano na pesquisa "O Direito à Memória e à Verdade dos Povos Indígenas", do Mestrado em Direitos Humanos pela Universidade de Brasília - UnB. Além disso, as artes plásticas e o ofício de professora são caminhos por onde ela trilha uma luta por menos desigualdades para as identidades indígenas. 


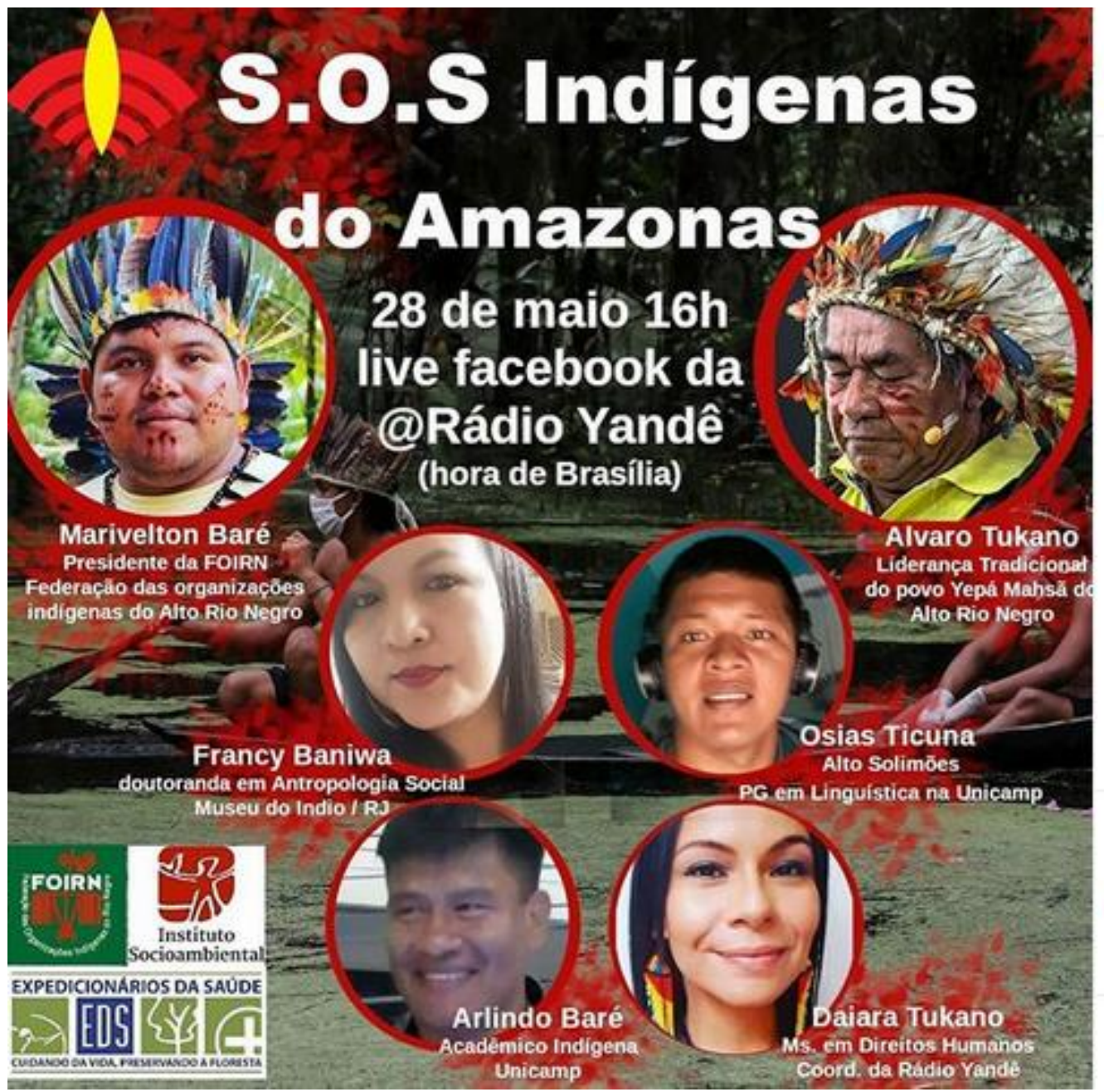

daiaratukano - Seguindo

daiaratukano A campanha SOS Indígenas do Amazonas precisa do seu apoio para arrecadar fundos para o envio de alimentos, produtos de higiene, oxigênio, medicamentos e equipamentos de proteção individual para profissionais da saúde que estão na linha de frente do atendimento e ajudar no envio de equipes de médicos, enfermeiros e técnicos de enfermagem para auxiliar o enfrentamento do covid nestas regiões. Não podemos deixar que os povos tradicionais do Brasil morram.

Os recursos financeiros arrecadados irão ser destinados para -...........................

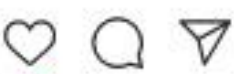

(1) Curtido por visibilidadeindigena $e$ outras 171 pessoas

Fonte: https://www.instagram.com/p/CAvUmctnqto/

A imagem de divulgação da live disponibilizada pelo perfil do Instagram de Daiara Tukano, contou com a participação das lideranças indígenas Marivelton Baré e Álvaro Tukano. Além deles, três indígenas acadêmicos de diferentes universidades brasileiras também participaram deste evento com objetivo de arrecadar mantimentos para os indígenas do estado do Amazonas.

Com toda esta riqueza de imagens nessa postagem, para analisá-la, vou tomar a definição de intericonicidade.

A intericonicidade supõe, portanto, dar um tratamento discursivo às imagens, supõe considerar as relações entre imagens que produzem os sentidos: imagens exteriores ao sujeito, como quando uma imagem pode ser inscrita em uma série de imagens, uma arqueologia, de modo semelhante ao enunciado em uma rede de formulação, em Foucault; mas também imagens internas, que supõem a consideração de todo conjunto da memória da imagem no indivíduo e talvez também os 
sonhos, as imagens vistas, esquecidas, ressurgidas ou fantasiadas que frequentam o imaginário. (COURTINE, 2011, p.160)

No momento em que nossos olhos se debruçam sobre a imagem dos corpos na postagem: as lideranças com seus cocares de penas coloridos e grafismo corporal impresso no rosto deixam, nossa memória percorrer o conjunto das memórias visuais sobre indígenas em uma série de imagens na elaboração de "uma arqueologia, de modo semelhante ao enunciado em uma rede de formulação" (COURTINE, 2011). Ela apresenta como plano de fundo, um rio e nele uma canoa com dois indígenas, um na popa e outro na proa da pequena embarcação. Eles estão utilizando máscaras e luvas cirúrgicas, numa alusão à infestação bacteriológica mundial causada pelo Coronavírus.

O título da live "S.O.S Indígenas do Amazonas" dialoga com o enunciado verbal produzido por Daiara. Nele, a comunicadora recorre à solidariedade e adesão do leitor em relação ao difícil momento que os indígenas da região Norte estão atravessando em função da pandemia. $\mathrm{O}$ enunciado verbal postado por Tukano pede o apoio para a arrecadação de materiais de higiene pessoal, alimentos, materiais hospitalares e de proteção para a equipe de saúde envolvida no tratamento dos povos originários do Amazonas.

O "S.O.S Indígenas do Amazonas", revela a distopia que, no grego antigo, significa literalmente "lugar ruim". A web, neste enunciado, torna-se lugar para denunciar a forma precária como as sociedades indígenas atravessam o período pandêmico. Sob um regime autoritário promovido pelo atual presidente brasileiro, muitas comunidades de povos originários encontram-se em situação de desespero por não receber do Estado nenhuma forma de auxílio para o combate, prevenção e sobrevivência a uma forma de vírus altamente letal que atinge o mundo e, com mais intensidade, as comunidades em situação de vulnerabilidade como os povos indígenas.

Esta narrativa apresenta um fragmento da história, a história do presente, e arregimenta subjetividades indígenas que não se limitam apenas a uma identidade fixa, "pura", preservada da origem. A discórdia das coisas, o disparate como nos propõe Foucault, está em perceber diferentes regimes de visualidades regidos pelas ordens do discurso de diferentes épocas. Além disso, o disparate também está em admitir que "a mudança do ambiente comunicacional afeta diretamente as normas de construção de significado e, portanto, a produção de relações de poder" (CASTELLS, 2019, p. 15). Daiara Tukano, como foi apresentada, é coordenadora da web rádio Yandê. Ela dirige semanalmente a programação digital da rádio que inclui articulações com indígenas do 
Brasil inteiro. Eles e elas utilizam mídias digitais, participam e se apropriam das novas tecnologias da comunicação e, definitivamente, mostram sua presença em espaços de luta e relações de poder na escrita de outras narrativas.

Os novos regimes de visualidades onde os indígenas estão inseridos circulam nos espaços da web, nesta amostra estão materializados no encarte eletrônico produzido pelos responsáveis pela divulgação da Rádio Yandê. Esta materialidade que envolve fotografia, a materialidade verbal e efeitos digitais, fruto da convergência dos meios de comunicação que envolve o "fluxo de conteúdos através de múltiplos suportes midiáticos" (JENKINS, 2008 , p. 27), requer um gesto de leitura que observe atentamente os elementos que a compõe. A sua interpretação acontece pela observação atenta às cores, formas, símbolos e palavras presentes nessa superfície e, são portadores de sentidos que revelam discursos, temporalidades, além principalmente do envolvimento dos sujeitos e sujeitas indígenas como enunciadores ativos de sua história do presente.

No papel de produtores e consumidores, inseridos em uma cultura participativa que "contrasta com as noções mais antigas sobre a passividade dos espectadores dos meios de comunicação" (JENKINS, 2008, p.28), os indígenas que produziram esses enunciados apresentam elementos importantes para sua interpretação e para a localização desses sujeitos e sujeitas distantes das formas de narrar do colonizador. Elas se afastam da versão tendenciosa da história que intencionou compreendê-los fossilizados em uma identidade imutável, em estado de "perfeição", como nos enunciados que forjaram suas subjetividades no início do processo de colonização brasileira.

Nessa direção, os elementos em diálogo na imagem no ambiente da web, como a logomarca da web Rádio Yandê, o cocar, os símbolos de organizações indígenas como FOIRN, o uso de roupas, maquiagens e acessórios ocidentais como fones de ouvido revelam nessa enunciação fraturada, a descontinuidade histórica que irrompe em uma emergência, que os inscreve no ponto de "entrada nas cenas das forças; é sua interrupção, o salto pelo qual elas passam dos bastidores para o teatro" (FOUCAULT, 2015, p. 67).

O protagonismo de mulheres indígenas está imbricado com a atuação delas na política, na liderança de movimentos e nas diferentes e criativas formas que encontram para proteger seus corpos, territórios e cosmologias. Por outro lado, o protagonismo também remete a sua atuação, no papel principal em narrativizar suas histórias. Em ambas as situações, as narrativas desenvolvidas nos espaços da web por essas mulheres indígenas, feminizam e tornam mais diversos os espaços por onde elas circulam e que constituem seu fazer ativista. 


\section{Escritas de si na web: práticas de resistência e o cuidado de si}

O enunciado a seguir (figura 03), foi elaborado por Célia Xakriabá Mindã Nynthê ${ }^{1}$, do estado de Minas Gerais. A ativista articula ao seu ativismo indígena à escrita poética e à educação indígena. Cientista social, mestre em Sustentabilidade Junto a Povos e Terras Tradicionais pela UNB, onde realizou a pesquisa "O Barro, o Genipapo e o Giz no Fazer Epistemológico de Autoria Xakriabá: reativação da memória por uma educação territorializada" (CORREA XAKRIABÁ, 2018).

Em sua perspectiva, como indígena e educadora, interessada em produzir uma educação intercultural, a escola tem funcionado historicamente como "ferramenta moderna de colonização". Neste sentido, ela propõe "indigenizar a escola”. Xakriabá nos apresenta formas de compreender a educação a partir das singularidades dos povos indígenas, "kayaponizar" ou "guaranizar" as práticas escolares. Em outras palavras, trazer para a escola indígena de cada povo maneiras próprias de concebê-la: "refletir sobre os saberes e os fazeres presentes no território, analisando as experiências de educação indígena mesmo antes da presença da escola e depois do amansamento dessa" (CORREA XAKRIABÁ, 2018, p. 09). Atualmente Célia cursa doutorado em Antropologia na Universidade Federal de Minas Gerais (UFMG).

A postagem de Célia Xakriabá (figura 03), em seu perfil do Facebook, representa uma amostra de escrita/exercício de si que narrativiza as formas de se perceber no mundo e, naturalmente, como as mulheres indígenas reagem às emergências históricas nas fronteiras culturais em que vivem.

\footnotetext{
${ }^{1}$ Célia Nunes Correa, assim como todas as outras identidades indígenas que nascem em território nacional têm seus nomes e sobrenomes registrados em cartório. Geralmente, esse registro costuma carregar nomes não-indígenas. Além desta opção, eles e elas utilizam em espaços sociais seu primeiro nome seguido do nome de sua etnia como uma maneira de marcar suas identidades originais. Podemos compreender esta alternância de usos de nomes, à luz da teoria de Mignolo (2003), como uma materialização de formas fraturadas das identidades brasileiras assumidas por muitos e muitas indígenas que carregam o orgulho de suas origens.
} 
Figura 03: Célia Xakriabá e a Desobediência
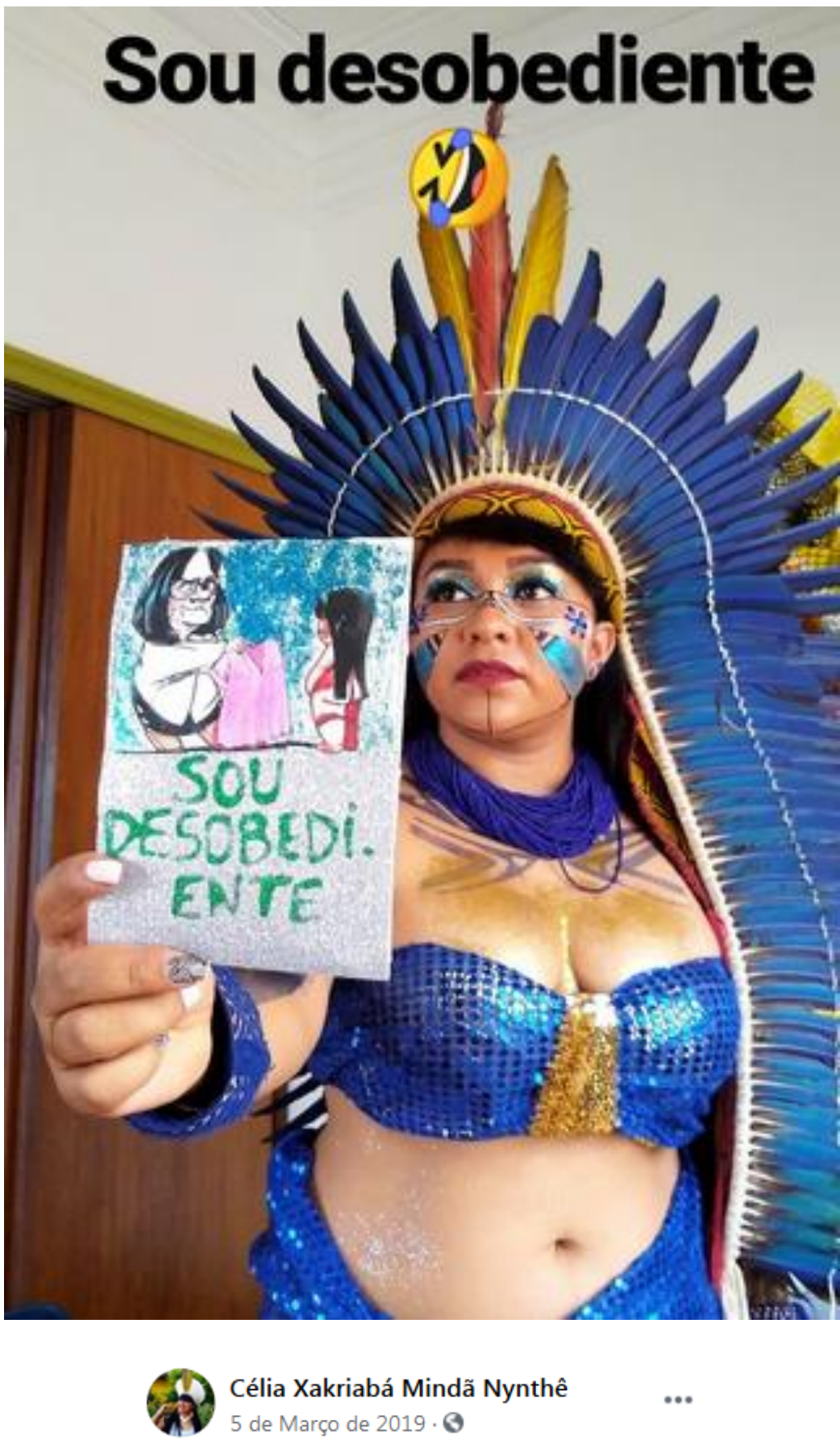

5 de Março de 2019 . 6

Da nova era que chegou no Brasil, anunciado pela Ministra do Ministério da Família, mulher e Direitos Humanos, mulher que viu Jesus no pé da Goiabeira $\Theta$. Só pra subverter eu vou de blue/azul, só pra desobedecer, porque a rebeldia também é um ato revolucionário.

(1):314 14 comentários 26 partilhas

Fonte:

https://www.facebook.com/photo.php?fbid=1139357119557492\&set=t.100004496437989\&type=3 
Os elementos da imagem deixam ver um corpo jovem, com adorno de penas azuis, amarelas e vermelha ao centro. Este formato de cocar, hoje muito utilizado pelas mulheres indígenas ativistas, na cultura de muitas sociedades indígenas, como dos Suruí-Aikewára (NEVES; CORRÊA, 2011) e dos Tembé-Tenetehara (NEVES; CARDOSO, 2015), é uma prerrogativa dos homens, os das mulheres, normalmente são menores, mas esta não é uma regra que não possa ser flexibilizada entre eles.

O colorido do corpo de Célia Xacriabá traz os tons azuis e perolados, feitos com cosméticos industrializados, no contorno dos seus olhos, formando uma sombra, e espalhados no seu abdômen. O brilho de glitter azulado ganhou formas de grafismos indígenas tanto em seu rosto, como no seu colo. As duas peças de roupa, assim como a braçadeira, igualmente em tons de azul brilhante, afirmam o lugar de enunciação que ela deseja marcar. Pela composição utilizada, o lugar de enunciação de Célia Xakriabá assinala sim uma identidade indígena, mas uma identidade em movimento, que se constrói nas fronteiras culturais, sem parâmetros fixos.

A imagem que nos mostra um excesso de brilho e data da postagem, realizada em 05 de março de 2019, mostra que foi feita no período do carnaval daquele ano. Mais uma vez, nossa memória das imagens nos faz inscrever o enunciado visual de Xakriabá em uma série composta por imagens referentes ao carnaval. Neste trabalho arqueológico o enunciado entra em uma rede de formulação com as imagens vistas que frequentam nosso imaginário e produzem sentidos que deslocam e reposicionam culturas e identidades. Nesta direção, Célia Xakriabá utiliza elementos de sua identidade indígena em contato com a cultura ocidentalizada do carnaval e coloca na "avenida" das redes sociais a situação da política atual brasileira.

O excesso de azul, nessa imagem, funciona como ativador da memória que construiu representações em azul para o gênero masculino, suscitadas pela fala da ministra Damares Alves, no início do governo de Jair Bolsonaro em 2019. Por suas posições controversas, que privilegiavam um discurso de extrema-direita nas redes sociais, neste período, era comum usuários se referirem a ela como "Sinistra" da Família, Mulher e Direitos Humanos.

Na postagem, o enunciado verbal "sou desobediente", não deixa nenhuma dúvida sobre sua posição discursiva. Em sua mão, ela exibe um desenho onde aparece a representação da ministra diante de uma menina indígena de cabelos lisos e longos, com grafismos no rosto, a quem ela estica os braços com uma blusa rosa. Essas duas cores, 
azul e rosa, representam no discurso da ministra, o binarismo existente na sua concepção retrógrada sobre gênero.

Xakriabá, sobre "a nova era" brasileira, demonstra conhecer bem o discurso da representante do Ministério da Família, Mulher e Direitos Humanos, muito visibilizada internacionalmente como uma pessoa insana, entre outras razões, porque "viu Jesus na goiabeira". Na postagem, a ministra não a representa e sua posição não lhe dá o poder de ditar normas em direção aos corpos de meninas e mulheres indígenas. Os discursos sexistas de Damares, alvos da "desobediência" de Célia, elaboram um certo modo de ser mulher, indígena e politicamente atenta. O enunciado de Célia Xakriabá inscreve-se em uma estética/ética que reflete uma prática revestida de resistência.

A partir dessa movimentação de discurso expressa nos enunciados de Célia, podemos remontar à definição de Michel Foucault (2004, p. 268) sobre o cuidado de si. O autor, referindo-se ao mundo greco-romano na Antiguidade, identifica na posição de alguns sujeitos "o modo pelo qual a liberdade individual ou a liberdade cívica, até certo ponto foi pensada como ética". Ocupar-se de si mesmo é cuidar de si. Nesta direção, a posição de ser "desobediente" é dizer não a um discurso que pretende reordenar as formas de ser das identidades originárias. A subversão à ordem presente na narrativa de si de Xakriabá representa que o cuidado de si implica também a relação com o outro, é o exercício de uma ética que permite administrar os espaços de poder presentes nas relações sociais.

Deslocando as análises de Foucault para pensar em como as mulheres indígenas se constituem como sujeitas, podemos afirmar que esse exercício "não é sobre o fundo de uma identidade psicológica, mas por meio de práticas que podem ser de poder ou de conhecimento, ou ainda por técnicas de si" Foucault (2004, p. 236). A resposta de Célia Xakriabá para a ministra Damares ainda nos faz refletir e compreender o enunciado como um recorte no arquivo que expõe a história do presente. Além disso, ele expõe os jogos que ordenam as verdades de uma época por meio dos discursos. Sobre estas questões discorre Neves-Corrêa (2018, p. 25):

A pergunta que podemos fazer, então, é como recortar um pequeno pedaço de um Arquivo, o domínio das coisas ditas, para contar uma história do presente. Em seu célebre livro A ordem do Discurso, Foucault nos apresenta sua visão sobre o perigo de tomar a palavra e dos jogos que ordenam as produções de verdades por meio de discursos. Foucault nos mostra que nada é dito por acaso, que há o que se pode dizer e o que se deve calar. Ao trabalhamos nesta perspectiva, podemos observar a aparição ou o apagamento de um determinado discurso em várias materialidades ao longo da história. Assim, é possível procurar 
uma série de materialidades que se ligam umas às outras por meio dos discursos, mas em descontinuidades, não como uma via que segue uniformemente uma espécie de linha do tempo.

Os discursos de Célia Xakriabá e Daiara Tukano visibilizados em seus enunciados, nos apresentam via web uma atitude que firma oposição às pesquisas da origem que pretendem por meio de uma reconstrução historiográfica, a narrativização em busca de uma suposta origem enunciada por sujeitos que historicamente, em seus lugares privilegiados socialmente, subalternizaram sujeitos e sujeitas indígenas sob a máscara de uma identidade homogeneizadora, considerados como aculturados e desprovidos de conhecimentos.

O objetivo desse trabalho, por outro lado, é a observação das descontinuidades, é descortinar os jogos de dominações, nos quais se destacam as estratégias e se estabelecem como os espaços de investigação a convivência entre as relações de poder e as práticas de resistência. Por meio da analítica do poder de Michel Foucault, observamos aqui a “definição do domínio específico formado pelas relações de poder e a determinação dos instrumentos que permitem analisá-lo" (FOUCAULT, 2015, p. 92). Por essa razão, as práticas de resistência elaboradas pelas indígenas ativistas presentes nesse artigo, representam os micropoderes das margens, onde as relações de poder também são produzidas.

\section{Considerações finais em movimentos}

As narrativas de mulheres indígenas nos espaços convergentes da web nos ensinam a partir de seus enunciados que "o cuidado de si é certamente o conhecimento de si” Foucault (2004, p. 271). Não é possível cuidar de si sem se conhecer. Este cuidado de si, não deve ser compreendido de maneira individual, ao contrário, cuidar de si implica cuidar bem dos outros.

Nosso pensamento foi criado a partir da articulação dos discursos dos saberes e poderes de uma lógica colonial que nos ensinou a não ver as singularidades subjetivas e as formas de resistência elaboradas pelos povos originários. Eles e elas foram narrativizados como selvagens, canibais, bárbaros etc. $\mathrm{O}$ ativismo de mulheres indígenas e seus discursos na web podem representar formas para a descolonização desse pensamento. O corpo e a comunicação, elementos que estão presentes nas culturas humanas ao longo de suas existências e constituem as escritas de si como práticas de 
resistência destas mulheres, podem tornar visíveis a partir dos diálogos nos espaços da internet as especificidades e os saberes das subjetividades indígenas.

A observação atenta aos enunciados e discursos produzidos por Daiara Tukano e Célia Xakriabá revela o lugar de enunciação de onde olhamos para este novo formato de narrativa das mulheres indígenas na web. São formas contemporâneas de contar e de produzir subjetividades cada vez mais fraturadas e espraiadas.

Expostas mundialmente nos espaços da internet elas desvelam suas lutas e formas fragmentadas de identidades, construídas nas fronteiras entre as tradições indígenas e seus diálogos com o universo ocidentalizado. Estas narrativas interagem com a cultura da convergência, atentas às transformações tecnológicas e à importância de ocupar novos lugares de poder. As mulheres indígenas ativistas assumem em postagens nas redes sociais formas cambiantes que conduzem o leitor dessas narrativas a outros lugares na $w e b$, produzindo um efeito fragmentado ou alinear a estas histórias.

A reflexão sobre as narrativas ativistas de mulheres indígenas nos espaços da web, também acontece na articulação de suas redes de memórias com uma tecnologia que permite observá-las em diversas temporalidades, espacialidades, outros regimes de visualidades e inseridas como protagonistas nas redes nas quais os poderes se desenvolvem. Toda essa articulação nos faz lançar novas formas de produzir sentidos para as subjetividades de mulheres indígenas e suas formas plurais de elaborações ativistas. Nesse protagonismo, as vozes das indígenas ativistas presentes neste estudo envolvem-se em diversos movimentos e lutas. Entretanto, na compreensão das vozes delas, devemos ter o pensamento norteador alicerçado pelo discurso da diversidade.

\section{Referências}

CASTELLS, M. Redes de indignação e esperança: movimentos sociais na era da internet (teaser). São Paulo: Zahar, 2019.

CORREA XAKRIABÁ, Célia Nunes. O Barro, o Genipapo e o Giz no fazer epistemológico de Autoria Xakriabá: reativação da memória por uma educação territorializada/, Célia Nunes Correa Xakriabá. Brasília - DF, 2018. 218 p.

COURTINE, J-J. Intericonicidade: entrevista com Jean-Jacques Courtine. [out. 2005]. Entrevistador: Nilton Milanez. Local: Sorbonne Nouvelle, Paris, 2005. Registro audiovisual. Disponível em: http://vimeo.com/4986725. Acessado em: 06/09/2012. 
COURTINE. Discurso e imagens: para uma arqueologia do imaginário. In: PIOVEZANI, C; CURCINO, L; SARGENTINI, V. Discurso, semiologia e história. São Carlos: Claraluz, 2011.

FOUCAULT, Michel. "A ética do cuidado de si como prática da liberdade". In: Ditos \& Escritos V - Ética, Sexualidade, Política. Rio de Janeiro: Forense Universitária, 2004.

FOUCAULT, M. A arqueologia do Saber. Rio de Janeiro: Forense Universitária, 2005.

FOUCAULT, Michel. Microfísica do Poder. Rio de Janeiro: Paz e Terra. 2015.

GREGOLIN, M.R. Discursos e imagens do corpo: heterotopias da (in)visibilidade na WEB. In: FLORES, G.G.; NECKEL, N.R.F.; GALLO, S.M.L. (org). Análise de discurso em rede: cultura e mídia. Campinas: Pontes, 2015, p. 191-213.

HARTMANN, T. A Contribuição da Iconografia para o Conhecimento dos Índios Brasileiros do Século XIX. Coleção Museu Paulista, Série Etnologia, v1, São Paulo, USP, (1975).

JENKINS, H. Cultura da convergência. São Paulo: Aleph, 2008.

MILANEZ, Nilton. Corpo cheiroso, corpo gostoso. Unidades corporais do sujeito no discurso. In: Acta Scientiarum. Language and Culture. Vol. 31. № 2. Maringá, 2009. disponível em:

http://periodicos.uem.br/ojs/index.php/ActaSciLangCult/article/view/6684/6684 >. Acesso em: 20 jun. 2020.

NEVES CORREAA, Maurício. (Tese de doutorado). Heterotopias no país do milagre: os corpos indígenas e as histórias filmadas. UNESP - Araraquara. 2018.

NEVES, Ivânia; CARDOSO, Ana (2015). Patrimônio cultural Tembé-Tenetehara. Belém: Iphan.

NEVES, Ivânia; CORREA, Maurício. Sentidos da Pele Aikewára: urucum, jenipapo e carvão. Belém: Editora UNAMA. 2011. 